DE-FG02-06ER64347 Final Report

\title{
Heritable Genetic Changes in Cells Recovered From Irradiated 3D Tissue Constructs
}

Michael Cornforth, Principle Investigator

Combining contemporary cytogenetic methods with DNA CGH microarray technology and chromosome flow-sorting increases substantially the ability to resolve exchange breakpoints associated with interstitial deletions and translocations, allowing the consequences of radiation damage to be directly measured at low doses, while also providing valuable insights into molecular mechanisms of misrepair processes that, in turn, identify appropriate biophysical models of risk at low doses. The following aims apply to cells recovered from 3D tissue constructs of human skin and, for the purpose of comparison, the same cells irradiated in traditional $2 \mathrm{D}$ cultures. The project includes research complementary to NASA/HRP space radiation project.

Individual Aims (as originally proposed)

1. Analyze by multi-flour fluorescence in situ hybridization (mFISH) the chromosomes in clonal descendents of individual human fibroblasts that were previously irradiated with ${ }^{137} \mathrm{Cs} \gamma$ rays or $1 \mathrm{GeV} /$ nucleon ${ }^{56} \mathrm{Fe}$ ions. Study the transmission of simple versus complex exchange aberrations with respect to chromosomal instability within each clone, and with respect to yields of aberrations observed in cells that were instead analyzed at the first mitosis following irradiation. Determine whether the relative yield of complex aberrations in cells showing long-term survival can be used as an LET-dependent biomarker of past exposure.

2. Examine irradiated clones from Aim 1 for submicroscopic deletions by subjecting their DNA to comparative genomic hybridization $(\mathrm{CGH})$ microarray analysis. Determine the dose response for the induction of submicroscopic deletions [to include clones whose progenitor cells were exposed to doses as low as 5 cGy of $\gamma$ rays; to include fluences as low as 1 particle traversal per cell for ${ }^{56} \mathrm{Fe}$ ions]. Compare results to the yield of spontaneous deletions for the purpose of determining signal-to-noise ratio and the lower dose limit of detection. Assess the frequency of co-deletion associated with translocations for the purposes of (1) augmenting at the submicroscopic level the prospective use of complex aberrations as an LET-dependent biomarker and (2) addressing the proposition that exchange aberrations are the result of homology-directed misrepair.

3. Flow-sort aberrant chromosomes from clones containing stable radiation-induced translocations and map the breakpoints to within an average resolution of $100 \mathrm{~kb}$ using the technique of "array painting". Examine clones that show "one-way" mFISH painting patterns (but without co-deletion) to determine whether these rearrangements are the result of a cryptic translocation breakpoints within the subtelomeric DNA of the (presumptive) recipient chromosome. Time permitting, in a select number of clones carrying translocations, sequence 
the DNA across the breakpoints involved, in order to provide evidence for (or against) the involvement of homology-directed recombination as the underlying molecular mechanism.

\section{Compilation of Results}

24-color mFISH was used to construct dose response curves for structural rearrangements in chromosomes for hTERT-immortalized human fibroblasts exposed to either ${ }^{137} \mathrm{Cs}$ gamma rays or $1 \mathrm{GeV}{ }^{56} \mathrm{Fe}$ ions. Results, which in this case were confined to chromosome-type aberrations produced in cells reaching the first post-irradiation mitosis. For doses in the range of 1-4 Gy for gamma rays, the dose response was predictably curvilinear. The aberration yield produced by the 1 Gy dose was easily statistically resolvable above background, and we predict that the experimental system has ability to resolve the effects of doses down to about $0.5 \mathrm{~Gy}$, although this would require scoring many more cells. It was judged that resolving damage produced by doses lower than $0.1 \mathrm{~Gy}$ would require a massive expenditure of resources, in terms of the number of mFISH karyotypes required, and therefore elected to defer a consideration of this

proposition at a future time. The response for aberrations produced by

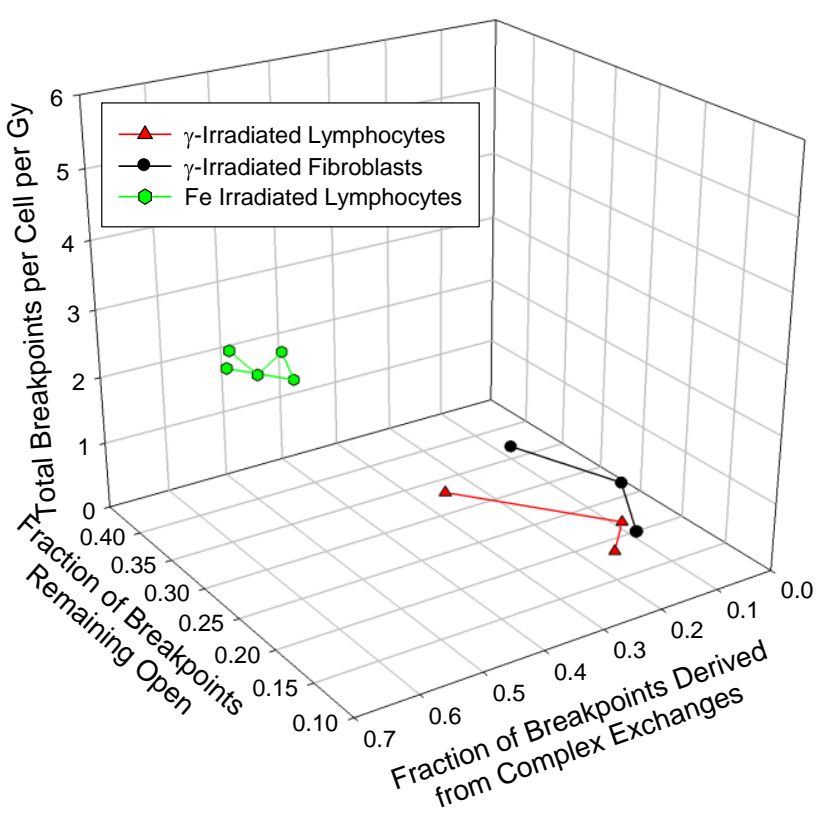
exposure to ${ }^{56} \mathrm{Fe}$ ions was much steeper per unit dose. The shape of the response curve was nearly linear with dose- although interestingly and quite unexpectedly - a slight degree of upward curvature was resolvable. Doses in the range of 0.2-1.5 Gy easily produced statistically resolvable increases in aberration yields above background. Since the lower limit of this dose range approaches that of single particle fluences, it was deemed unnecessary to go to lower doses in order to characterize the shape of the dose response. For both radiation types, we constructed a 3D plot of total aberration breakpoints versus

breakpoints derived from complex aberrations versus the frequency of "open" breakpoints (i.e. those deriving from terminal deletions and incomplete exchanges). This resulted in a predictable biodosimetric relationship in which damage from Low versus High LET radiations could be readily discerned (see figure 1 above).

Regarding the clonal derivatives of single cells that survived exposure to radiation, we isolated, and characterized by mFISH, 94 independent human hTERT-immortalized clones that survived 
1-4 Gy exposures of $662 \mathrm{keV}$ gamma rays. Additionally, 84 clones surviving 1.0 Gy of 1 GeV/amu ${ }^{56}$ Fe ions were likewise isolated and karyotyped. [The clones were cryogenically preserved for further potential molecular analysis in aim 2.] The background frequency of translocations in 8 unirradiated clones, for which a total of 1039 cells were karyotyped, showed a sporadic background frequency of 0.004 translocations per cell. For the majority of irradiated clones, all ten karyotypes were normal by mFISH. However, following 4 Gy of gamma rays, $21 / 49$ clones $(43 \%)$ were homogeneous for a unique stable rearrangement that was present in $10 / 10$ karyotypes. Most of the recovered rearrangements were simple reciprocal translocations, but of the 21 clones harboring stable rearrangements, 4/21 (19\%) contained complex exchanges. Surprisingly similar results were obtained following exposure to ${ }^{56}$ Fe particles. Of the 84 clones examined, $30(36 \%)$ contained transmissible exchange aberrations present in all cells sampled; of these 8 (27\%) were complex, mostly involving small insertions. Interestingly, the frequency of clones containing (homogeneous) stable translocations was equal to the frequency of translocations per cell in an irradiated non clonal population that was sampled at the first postirradiation mitosis. This is irrespective of the fact that cells at the first mitosis frequently contained lethal aberrations, such a dicentrics.

Some clones irradiated with either gamma rays or ${ }^{56} \mathrm{Fe}$ ions were found to contain, in addition to stable rearrangements, additional aberrations involving one cell out of the ten that were karyotyped. Often these took the form of truncated chromosomes (not apparently involved in the parental exchange configuration) which were either terminal deletions or "one-way" exchanges. Sometimes these "sporadic" aberrations were reciprocal translocations, again, not associated with the parental exchange. We initially hypothesized that these may represent instances of delayed chromosomal instability. However, after more careful quantitative analysis, we concluded that both types of these sporadic events may be explained on the basis of background frequencies of aberrations present in the unirradiated controls. Thus, in our experimental model system neither gamma rays nor HZE heavy ion irradiation induced genomic instability capable of causing large-scale chromosomal rearrangements in these cells.

The use of the MatTek artificial skin model in these studies, and it subsequent use as material for DNA microarray analysis (aim 2) was compromised by the following situation. The mitotic index for cells reaching their first postirradiation mitosis was far too low to provide a suitable number of scorable metaphases to make mFISH feasible. This also brought into question whether such data would be representative of damage to the cell population. Nevertheless, we were able to collect pertinent data using this system by exposing bulk non clonal cell populations to doses of $0,2,4$ or $6 \mathrm{~Gy}$ of gamma rays, deferring the preparation of metaphases by several days, during which time surviving cells were allowed to proliferate. Bulk cultures were then examined by mFISH. Irradiations were conducted in two ways. For In situ irradiations whole skin constructs were exposed, and the dermal layer surgically teased away. For In vitro irradiations the dermal layer of the skin construct was first dissociated into single cells prior to irradiation. In both 


\begin{tabular}{|c|c|c|c|c|c|c|c|}
\hline & 0 Gy in vitro & 0 Gy in situ & 2 Gy in vitro & 2 Gy in situ & 4 Gy in situ & 6 Gy in vitro & 6 Gy in situ \\
\hline Cells & 239 & 98 & 105 & 132 & 203 & 149 & 30 \\
\hline $\begin{array}{l}\text { Complete Translocations } \\
\text { per Cell }\end{array}$ & 0 & $0.010 \pm 0.010$ & $0.349 \pm 0.051$ & $0.187 \pm 0.026$ & $0.591 \pm 0.054$ & $1.087 \pm 0.085$ & $0.700 \pm 0.153$ \\
\hline $\begin{array}{l}\text { Incomplete Translocations } \\
\text { per Cell }\end{array}$ & 0 & 0 & 0 & 0 & $0.005 \pm 0.005$ & 0 & 0 \\
\hline $\begin{array}{l}\text { One-Way Translocations } \\
\text { per Cell }\end{array}$ & 0 & $0.010 \pm 0.010$ & $0.038 \pm 0.017$ & $0.043 \pm 0.013$ & $0.113 \pm 0.024$ & $0.027 \pm 0.013$ & 0 \\
\hline $\begin{array}{l}\text { Total Translocations per } \\
\text { Cell }\end{array}$ & 0 & $0.020 \pm 0.014$ & $0.386 \pm 0.054$ & $0.230 \pm 0.029$ & $0.709 \pm 0.059$ & $1.114 \pm 0.086$ & $0.700 \pm 0.153$ \\
\hline $\begin{array}{l}\text { Complete Dicentrics per } \\
\text { Cell }\end{array}$ & $0.004 \pm 0.004$ & 0 & 0 & 0 & 0 & 0 & 0 \\
\hline $\begin{array}{l}\text { Incomplete Dicentrics per } \\
\text { Cell }\end{array}$ & 0 & 0 & 0 & 0 & 0 & 0 & 0 \\
\hline $\begin{array}{l}\text { One-Way Dicentrics per } \\
\text { Cell }\end{array}$ & 0 & 0 & $0.008 \pm 0.008$ & $0.004 \pm 0.004$ & 0 & 0 & 0 \\
\hline Total Dicentrics per Cell & $0.004 \pm 0.004$ & 0 & $0.008 \pm 0.008$ & $0.004 \pm 0.004$ & 0 & 0 & 0 \\
\hline $\begin{array}{l}\text { Interstitial Deletions per } \\
\text { Cell }\end{array}$ & $0.008 \pm 0.006$ & $0.010 \pm 0.010$ & 0 & $0.004 \pm 0.004$ & $0.005 \pm 0.005$ & 0 & 0 \\
\hline $\begin{array}{l}\text { Simple Exchanges per } \\
\text { Cell }\end{array}$ & $0.012 \pm 0.007$ & $0.031 \pm 0.018$ & $0.394 \pm 0.038$ & $0.237 \pm 0.029$ & $0.729 \pm 0.060$ & $1.114 \pm 0.086$ & $0.700 \pm 0.153$ \\
\hline $\begin{array}{l}\text { Terminal Deletions per } \\
\text { Cell }\end{array}$ & $0.029 \pm 0.011$ & 0 & 0 & $0.007 \pm 0.005$ & $0.026 \pm 0.015$ & $0.027 \pm 0.013$ & 0 \\
\hline $\begin{array}{l}\text { Acentric Fragments per } \\
\text { Cell }\end{array}$ & $0.004 \pm 0.004$ & $0.010 \pm 0.010$ & 0 & 0 & $0.009 \pm 0.009$ & 0 & 0 \\
\hline $\begin{array}{l}\text { Truncated Chromosomes } \\
\text { per cell }\end{array}$ & $0.008 \pm 0.006$ & 0 & $0.008 \pm 0.008$ & 0 & $0.009 \pm 0.009$ & 0 & $0.033 \pm 0.033$ \\
\hline $\begin{array}{l}\text { Complex Exchanges per } \\
\text { Cell }\end{array}$ & 0 & 0 & $0.030 \pm 0.015$ & $0.032 \pm 0.011$ & $0.138 \pm 0.026$ & $0.195 \pm 0.036$ & $0.200 \pm 0.082$ \\
\hline $\begin{array}{l}\text { Complex Exchange } \\
\text { Breakpoints per Cell }\end{array}$ & 0 & 0 & $0.106 \pm 0.028$ & $0.104 \pm 0.019$ & $0.488 \pm 0.049$ & $0.758 \pm 0.071$ & $0.700 \pm 0.153$ \\
\hline $\begin{array}{l}\text { Total Breakpoints per } \\
\text { Cell }\end{array}$ & $0.067 \pm 0.017$ & $0.071 \pm 0.027$ & $0.902 \pm 0.083$ & $0.586 \pm 0.046$ & $1.970 \pm 0.099$ & $3.013 \pm 0.142$ & $2.133 \pm 0.267$ \\
\hline $\begin{array}{l}\text { Number of Indentified } \\
\text { Clonal Subpopulations }\end{array}$ & ND & ND & 6 & 0 & 9 & 5 & 2 \\
\hline $\begin{array}{l}\text { Fraction of Cell in Clonal } \\
\text { Subpopulations }\end{array}$ & ND & ND & $0.136 \pm 0.032$ & 0 & $0.144 \pm 0.026$ & $0.550 \pm 0.061$ & $0.233 \pm 0.088$ \\
\hline
\end{tabular}

Table 2. Frequencies and Classes of Chromosome Aberrations: The frequencies of chromosome aberrations derived from cells irradiated in situ appear to be lower than those from cells irradiated in vitro. No such difference was observed in the non-irradiated control populations. This difference results from a decreased frequency of reciprocal translocations. This does not rule out the possibly that the initial frequencies of unstable aberrations (dicentrics, interstitial deletions terminal deletions, etc.) might be lower as well, since these are known to be eliminated from populations after a number generations post-irradiation. The table does not include data from cells irradiated with $4 \mathrm{~Gy}$ in vitro, as nearly all of these contained the same complex exchange (see Figure 1). A number of cytogenetically identifiable subpopulations were found in nearly all the treatment groups, with a higher frequency of cell involvement among the in vitro-irradiated cells. This result serves to complicate the interpretation of differences in aberration frequency between in situ and in vitro groups.. Abbreviations: ND = Not Done

cases, only the dermal layer of skin was used. Within cells of this irradiated bulk population, clear evidence of clonal expansion was observed. Several such clonal outgrowths were observed, as defined by two or more cells within the population that harbored the same aberration or constellation of aberrations. Five examples are shown in the Table below. Interestingly, two of these were harbored transmissible complex aberrations. In fact, clonal outgrowths containing complex exchanges were relatively common across the range of doses given. In one instance (data not shown) a single clonal outgrowth that homogeneously contained a 3-way complex exchange had completely taken over the culture at the expense of all other cells. Observations such as this raise the possibility that cells harboring complex rearrangements may enjoy a preferential growth advantage. For future experiments, the integration of hTERT-immortalized fibroblasts or cells representing radiation sensitive syndromes into the dermal layer of a 
"custom" 3D skin construct remains as an intriguing possibility, and MatTek has expressed interest in assembling these for us.

\begin{tabular}{|c|c|c|}
\hline 6 Gy in vitro & Number of Cells & Frequency \\
\hline Total Cells & 188 & 1.0 \\
\hline Normal Cells & 69 & 0.37 \\
\hline Cells With Exchanges & 117 & 0.62 \\
\hline \multicolumn{3}{|l|}{$\begin{array}{l}\text { Identified Clonal } \\
\text { Subpopulations }\end{array}$} \\
\hline $\begin{array}{l}\# 1 \\
\text { C: }\left(1-3-1^{\prime}\right)\left(3^{\prime}-7\right)\left(7^{\prime}-3\right) \\
\text { T: }\left(2^{\prime}-13\right)\left(13^{\prime}-2\right) \\
\text { T: }\left(11^{\prime}-Y\right)\left(Y^{\prime}-11\right)\end{array}$ & 4 & 0.02 \\
\hline $\begin{array}{l}\# 2 \\
\text { C: }\left(3-11^{\prime}\right)\left(11-3^{\prime}-10\right)\left(10^{\prime} T\right) \\
\text { T: }\left(9^{\prime}-16\right)\left(16^{\prime}-9\right)\end{array}$ & 21 & 0.11 \\
\hline $\begin{array}{l}\# 3 \\
\text { C: }\left(3^{\prime}-12\right)\left(12^{\prime}-8-3\right) \\
\text { T: }\left(11^{\prime}-17\right)\left(17^{\prime}-11\right)\end{array}$ & 7 & 0.04 \\
\hline $\begin{array}{l}\# 4 \\
\text { T: }\left(3^{\prime}-14\right)\left(14^{\prime}-3\right) \\
\text { T: }\left(12^{\prime}-18\right)\left(18^{\prime}-12\right)\end{array}$ & 67 & 0.36 \\
\hline $\begin{array}{l}\# 5 \\
\text { T: }\left(4^{\prime}-13\right)\left(13^{\prime}-4\right) \\
\text { T: }\left(9^{\prime}-11\right)\left(11^{\prime}-9\right) \\
\text { T: }\left(12^{\prime}-15\right)\left(15^{\prime}-12\right)\end{array}$ & 5 & 0.03 \\
\hline Total for Subpopulations & 104 & 0.55 \\
\hline
\end{tabular}

Table 1. Identified Clonal Subpopulations: This table provides a description of the clonal subpopulations found among the cells in the bulk culture irradiated with $6 \mathrm{~Gy}$ in vitro. Cytogenetically identifiable subpopulations were defined as three or more cells containing the same simple exchange or two or more cells showing the same complex exchange or group of simple and/or complex exchanges. All the subpopulations contained multiple exchanges, while three out of the five contained a complex exchange. It appears that a large amount of cytogenetic damage including complex exchanges is transmissible in surviving cells. As might be expected, the subpopulations from cultures irradiated with lower doses tended to have fewer exchanges and most of these were simple.

Nevertheless, two examples of a four-break complex exchange $\left[\left(5^{\prime}-8\right)(8 '-12)(12\right.$ '14)(14'-5)] were found in the 2 Gy in vitro culture, verifying that complex exchanges are often transmissible.
We return now to data derived from the hTERT-immortalized clones derived from Aim 1, which were not isolated from the MatTek artificial skin system. Analysis of the $2.1 \mathrm{Mb}$ DNA microarrays from NimbleGen was employed. Of the relatively small subset of clones thus far studied, several contain radiationinduced deletions, some of which are quite large, as exemplified in Figure 2 below. In this case, following $4 \mathrm{~Gy}$ exposure to gamma

rays, chromosome 11 in all cells within this particular clone suffered a $12 \mathrm{Mb}$-sized deletion that is clearly evident as a shift in the $\log 2$ ratio of red:green fluorescence. [Unaffected segments show a $\log 2$ ratio of 0.0 (pink horizontal line) whereas this ratio is shifted into the negative region for deletions. Each dot represents an average of a contiguous cluster of ten features from the 2.1 Mb-feature array.]

Pooling data from some half-dozen clones, it can be seen from the size frequency distributions (shown in the next figure) that most deletions are considerably smaller. In Figure 3A the distribution is shown on the megabase scale. It can be appreciated that most large deletions range in size between 0.5 to $1.0 \mathrm{Mb}$. To display the distribution for smaller deletions in sufficient detail the scale had to be changed. Figure 3B limits the inclusion of events to no greater than $0.5 \mathrm{Mb}(500 \mathrm{~kb})$. As can be seen, even at this level of resolution, smaller deletions dominate the frequency response. 

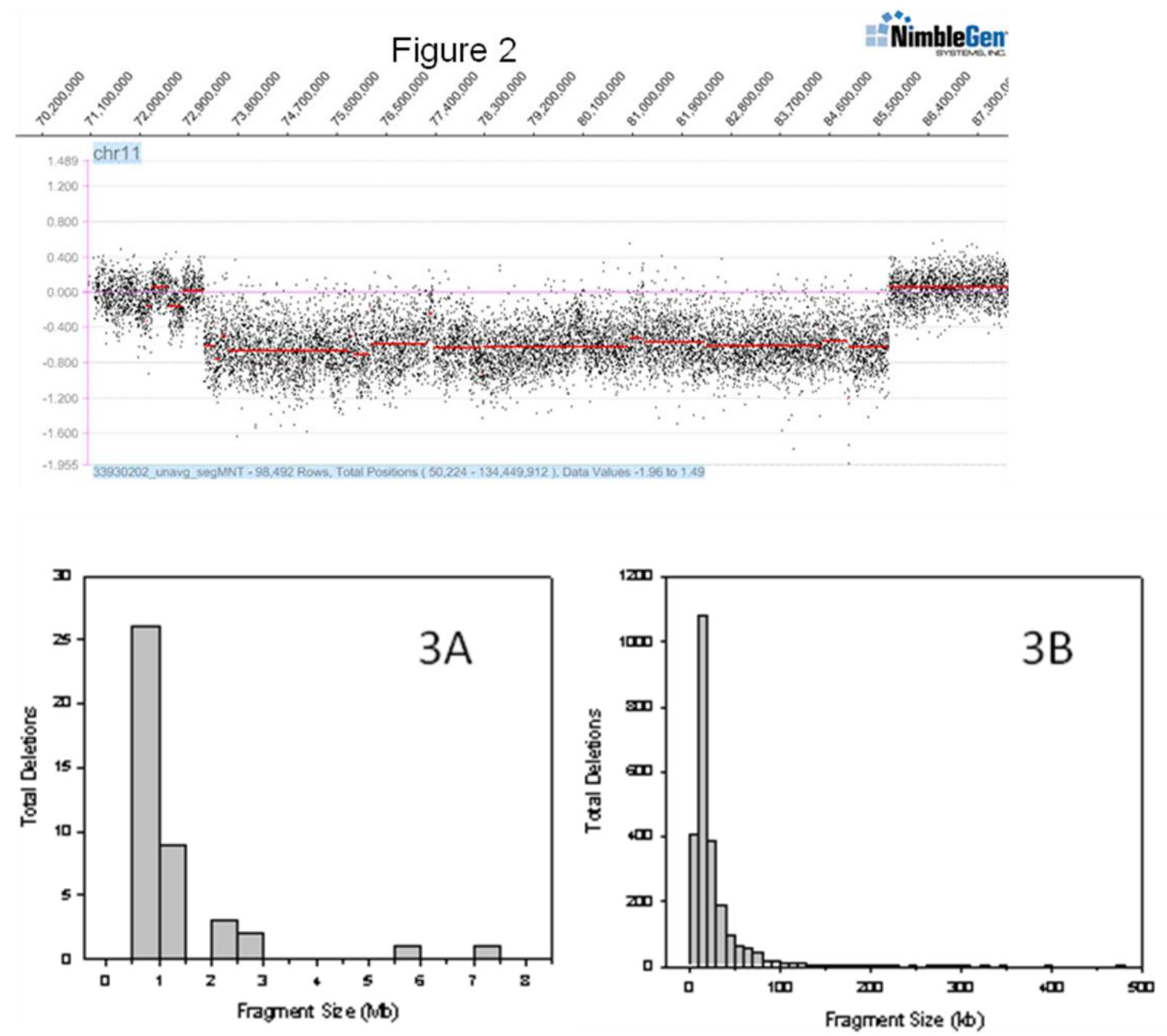

Dr. Ponomarev at NASA, has begun to model the theoretical size-frequency distributions of microdeletions for both high- and low LET, comparing various models of chromatin structure with actual data obtained using high density microarrays. Preliminary theoretical results of such modeling indicates that even reasonably dense DNA CGH arrays may be incapable of detecting the majority of interstitial deletions produced by radiation, as they are predicted to be too small. The use of next-generation $4.2 \mathrm{Mb}$ arrays from NimbleGen may be useful in this context.

For Aim 3 we had originally proposed to flow-sort aberrant chromosomes using the technique of "microarray painting" as a prelude to more extensive molecular analysis. At that time we had entered into an arrangement with Los Alamos National Laboratory's Flow Cytometry Resource for chromosome sorting. Unfortunately, key people involved in this prospective arrangement either retired or otherwise became unavailable for this project, largely the result of a systematic restructuring of the former Life Sciences Division. We briefly resurrected interest in this approach by considering collaboration with Nigel Carter of the Welcome Trust Sanger Institute in the UK who was, in principle, amenable to our request. However, it become evident during 
our discussions that such an arrangement constituted a formal collaboration that would soon involve us sending someone over to the UK for a period of months, and we lacked the resources for this sort of endeavor. Moreover, during this time frame impressive advances were made in the area of genome sequencing which, in principle, promised to make this approach eventually cost-effective for our purposes, and which may supersede array-based technologies. In an altogether separate, but tangentially pertinent, project, Dr. Joe Gray, Chair of Biomedical Engineering, Oregon Health \& Science University has agreed to sequence some half-dozen clones resulting from this project, and we should soon find out whether this approach gives us the information we seek, and to what extent it is cost-effective.

\section{Deliverables}

Levy, D., Reeder, C., Loucas, B., Hlatky, L., Chen, A., Cornforth, M. and Sachs, R. (2007) Interpreting chromosome aberration spectra. Journal of Computational Biology 14, 144-155.

Bailey, S.M. and Cornforth, M.N. (2007) Telomeres and DNA double strand breaks: Ever the twain shall meet? Cellular \& Molecular Life Sciences., 1420-1682X (Print) 1420-9071 (Online).

Bailey SM, Williams ES, Cornforth MN, Goodwin EH. Chromosome Orientation fluorescence in situ hybridization or strand-specific FISH.

Methods Mol Biol. 2010;659:173-83.

Williams ES, Cornforth MN, Goodwin EH, Bailey SM.

CO-FISH, COD-FISH, ReD-FISH, SKY-FISH.

Methods Mol Biol. 735:113-24, 2011.

R. Eberle, B.D. Loucas and M.N. Cornforth

Long Term Transmissibility of Chromosome Rearrangements in Human Cells Exposed to

Ionizing Radiation. Poster at the $13^{\text {th }}$ International Congress of Radiation Research, San

Francisco, CA., July 8-12, 2007.

J.S. Bedford and M.N. Cornforth

Controversies and Issues in Radiation Cytogenetics. Workshop co-chairs at the $13^{\text {th }}$ International Congress of Radiation Research, San Francisco, CA., July 8-12, 2007.

M. N. Cornforth and B. D. Loucas

HZE Particles Fail to Induce Chromosomal Instability in the Clonal Derivatives of Irradiated Human Cells. Poster at the $18^{\text {th }}$ Annual NASA Space Investigators' Workshop, Sonoma, CA, July 13-15, 2007. 
P. Hahnfeldt, D. Levy, R. Sachs, C. Reeder, A. Chen, B. Loucas, M. Cornforth and L. Hlatky Apparently Incomplete Chromosome Aberrations: Applicability to RBE Estimation and Biodosimetry. Oral presentation at the $18^{\text {th }}$ Annual NASA Space Investigators' Workshop, Sonoma, CA, July 13-15 2007.

Loucas, B.D. and Cornforth M.N. Characterization of Chromosome Damage in Dermal Fibroblasts Irradiated In Vitro versus In Situ In a 3D Human Skin Model. Poster presentation, NASA Space Investigators Workshop, Philadelphia, June 30-July 2, 2008.

M.N. Cornforth and B.D. Loucas. Microscopic and Submicroscopic Chromosome Rearrangements In the Progeny of Irradiated Human Fibroblasts: Future Comparisons Between Dermal Fibroblasts Exposed In Vitro and In Situ. Poster given at the DOE Low Dose Program Investigators' Workshop VI, Washington D.C. January 21-23, 2008.

M.N. Cornforth, "Chromosome Damage as a Function of LET, Dose and Dose Rate and Its Role in Risk from Radiation Exposure" Low Dose and Low dose rate Radiation Effects and Models. Invited Speaker: Annual Meeting of the National Council on Radiation Protection and Measurements (NCRP), Bethesda, MD; April 14-15, 2008.

Loucas, B.D. and Cornforth M.N. A comparison of radiation induced damage in normal human fibroblasts irradiated in vitro or in situ as part of the dermal layer of an artificial skin model system. Poster presentation at the 54th Annual Meeting of the Radiation Research Society, Boston, Sept. 21-24, 2008.

B.D. Loucas, R.L. Eberle, M. Durante, and MN Cornforth, Cytogenetic Signatures in the Patterns of Chromosome Aberrations Produced by Gamma-rays, Alpha particles and Heavy Ions. Poster presentation 17th International Chromosome Conference, Boone, NC, June 23-27, 2009.

B.D. Loucas and M.N. Cornforth. Unrejoined cytogenetic damage related to heavy ion irradiation. Platform presentation, Heavy Ions in Therapy and Space Symposium, Cologne, Germany, July 6-10, 2009.

B.D. Loucas, S.M. Bailey, R.L. Eberle and M.N. Cornforth. Next generation approaches to the analysis of structural chromosome aberrations: Emphasis on translocations and deletions produced by ionizing radiation. Platform presentation (MNC) 9th International Symposium on Chromosome Aberrations, St. Goar, Germany, July 11-12, 2009.

B.D. Loucas and M.N. Cornforth. Cells carrying radiation induced transmissible exchanges have a selective growth advantage. Poster presentation at the 55th Annual Meeting of the Radiation Research Society, Savannah, GA, October 3-7, 2009.

A.L. Ponomarev, M.N. Cornforth, B.D. Loucas, F.A. Cucinotta. A Monte-Carlo Model for the Formation of Radiation-Induced Chromosomal Aberrations. Presentation and poster at the Radiation Research Society, Savannah, Georgia. October 3-7, 2009. 
B.D. Loucas and M.N. Cornforth. Chromosome Damage in Cells Irradiated In Vitro Versus In Situ From a 3D Human Skin Model: The Influence of Clonal Expansion and Implications for Direct Low-Dose Measurement of Damage. Poster presentation Low Dose Radiation Research Investigators Workshop VIII, Bethesda, MD, April 6-8, 2009.

A.L. Ponomarev, M.N. Cornforth, B.D. Loucas, F.A. Cucinotta. The Distribution of Chromosomal Aberrations in Human Cells as Predicted by a Generalized Model of RadiationInduced Aberration Formation. Presentation, Space radiation Panel, International Academy of Astronautics. The 18th Symposium on Humans in Space, Houston, Texas. April 11-15, 2011.

A.L. Ponomarev, M.N. Cornforth, B.D. Loucas, F.A. Cucinotta.The Distribution of Small Ring Products and Associated Deletions in Human Chromosomes as Predicted by a Generalized Model of Radiation-Induced Aberration Formation. Presentation and poster at the $21^{\text {st }}$ Annual NASA Space Radiation Investigators' Workshop, Port Jefferson, New York. May 16-19, 2010

A.L. Ponomarev, M. N. Cornforth, B.D. Loucas, F.A. Cucinotta. A Monte-Carlo Model for the Formation of Radiation-Induced Chromosomal Aberrations. Poster at the RRS 2010 annual meeting at Maui, Hawaii. September 25-29, 2010. 